\title{
Avaliação qualitativa de cardápios oferecidos em escolas de educação infantil da grande São Paulo
}

\section{Qualitative evaluation of menus offered in primary schools in the metropolitan area of São Paulo}

Priscila dos Santos Boaventura'

Ana Carolina de Oliveira'

Juliana de Jesus Costa?

Patrícia Vieira Pio Moreira'

Andrea Carvalheiro Guerra Matias'

Mônica Glória Neumann Spinelli'

Edeli Simioni de Abreu'

' Centro de Ciências Biológicas e da Saúde, Curso de Nutrição. Universidade Presbiteriana Mackenzie. São Paulo, SP, Brasil.

Correspondência / Correspondence

Andrea Carvalheiro Guerra Matias

E-mail:acgmatias@gmail.com

\section{Resumo}

Objetivos: Avaliar qualitativamente as preparações do cardápio de escolas municipais da Grande São Paulo. Método: Avaliaramse qualitativamente pelo método de Avaliação Qualitativa das Preparações do Cardápio (AQPC) os cardápios mensais de escolas municipais das seguintes cidades: Barueri, Guarulhos, São Bernardo do Campo e São Paulo-SP. Resultados: Foi satisfatória a oferta de hortaliças. Embora a oferta de frutas tenha sido adequada, é constante a presença de doces. Dos cinco cardápios analisados, em três houve monotonia de cores em pelo menos uma das grandes refeições. Houve adequação com relação às técnicas de cocção de pratos proteicos. A carne bovina é a mais presente nos cardápios e há limitação da oferta de peixe. Conclusão: Conclui-se que o método AQPC é um bom instrumento de avaliação da qualidade das refeições, pois os alimentos não são ingeridos apenas por sua qualidade nutricional, mas em conjunto com suas características sensoriais. De modo geral, os cardápios avaliados estão adequados em relação à oferta de frutas, hortaliças e laticínios e às técnicas de cocção empregadas. No entanto, sugere-se a revisão da frequência do emprego de alimentos sulfurados e doces no cardápio.

Palavras-chave: Planejamento de Cardápio. Alimentação Escolar. Educação Alimentar e Nutricional. 


\section{Abstract}

Objectives: To perform qualitative assessment of menu preparations of municipal schools in Great São Paulo. Method: The monthly menus of municipal schools in the cities of Barueri, Guarulhos, São Bernardo do Campo and São Paulo (SP) were qualitatively evaluated by the method of Qualitative Assessment of Menu Preparations (AQPC). Results: The supply of vegetables was satisfactory. Although fruits have been adequately supplied, the presence of candies is constant. Of the five menus analyzed, in three there was color monotony in at least one of the large meals. There was appropriateness in relation to cooking techniques of protein dishes. Beef is the most present in the menus and the supply of fish is limited. Conclusion: It was concluded that the method used is a good tool for assessing the quality of meals, because food is not eaten only by its nutritional quality, but together with its sensory characteristics. In general the evaluated menus are adequate in relation to the supply of fruits, vegetables and dairy products and cooking techniques employed. However, it is suggested to review the frequency of the use of sulfur and sweet foods on the menu.

Key words: Menu Planning. School Feeding. Food and Nutrition Education.

\section{Introdução}

A criança tem seu comportamento alimentar moldado pela sociedade na qual está inserida. É durante essa etapa que os hábitos alimentares são formados, mas as crianças não possuem capacidade para escolher alimentos de acordo com seu valor nutritivo; sendo assim, os alimentos ingeridos são escolhidos pela experiência, observação e educação. Ela não se alimenta somente pela fome, mas também pelo ambiente e contexto social, no qual a família e a escola têm papel fundamental. ${ }^{1-4}$ Durante a infância, a alimentação equilibrada é de suma importância para garantir o crescimento e desenvolvimento adequado.,4

A alimentação oferecida nas creches tem ação direta sobre a formação dos hábitos alimentares, devido ao tempo que as crianças passam nesses locais. Os alimentos que fazem parte do cardápio escolar devem ser escolhidos adequando-se às necessidades das crianças; assim, a refeição servida 
deve conter frutas, vegetais, sucos de frutas, pães e biscoitos integrais, etc., e os alimentos de baixo ou nenhum valor nutritivo não devem ser incluídos. ${ }^{5,6} \mathrm{~A}$ adoção de práticas alimentares saudáveis por parte dos pré-escolares pode ser considerada importante instrumento de promoção à saúde, podendo interferir positivamente ou não na vida adulta desses indivíduos. ${ }^{3}$

Um cardápio consiste na sequência de preparações culinárias que compõem as refeições diárias ou de determinado período. Para atender às necessidades, tanto fisiológicas quanto sensoriais dos comensais, é necessário que o cardápio seja colorido, contenha alimentos de todos os grupos alimentares, tenha texturas equilibradas, possua alimentos comuns da região em que vivem, seja seguro do ponto de vista higiênico-sanitário e obedeça aos limites financeiros disponíveis, entre outros critérios. ${ }^{7}$ Além de nutricionalmente adequados, os cardápios oferecidos ao público infantil devem ser atrativos. ${ }^{4}$ Esses cardápios devem ser planejados por nutricionistas, a partir do diagnóstico do estado nutricional da clientela atendida em consonância com as normas do Fundo Nacional de Desenvolvimento da Educação (FNDE), para adequá-los às necessidades da população específica. ${ }^{8,9}$

O cardápio oferecido nas instituições de ensino deve ser adequado às necessidades dos alunos, às condições da escola e ao tempo em que aluno vai permanecer nesse ambiente. Deve conter alimentos de alto valor nutricional, proporcionando às crianças uma alimentação quantitativamente suficiente, qualitativamente completa, harmoniosa em seus componentes e adequada à sua finalidade e ao organismo a que se destina. ${ }^{3,7}$

O cardápio também pode ser utilizado como uma ferramenta de educação nutricional, pois os alimentos nele presentes podem servir como exemplo para uma alimentação saudável e equilibrada. É indispensável que os nutricionistas dessas instituições façam avaliações qualitativas periódicas dos cardápios, para que se mantenham adequados para a população a que se destinam, evitando assim desequilíbrios nutricionais. ${ }^{5}$

Com a finalidade de ajudar o profissional na elaboração de um cardápio apropriado do ponto de vista nutricional e sensorial, o método de Avaliação Qualitativa das Preparações do Cardápio (AQPC) analisa as preparações que o compõem, proporcionando uma visão global do mesmo. ${ }^{10}$

O planejamento do cardápio segundo o Programa Nacional de Alimentação Escolar (PNAE) deve considerar os aspectos nutricionais e sensoriais, como cores, textura, sabores, combinação de preparações, tipo de alimento e técnicas de preparo. ${ }^{11-13}$ Diante do exposto, este estudo teve por objetivo avaliar qualitativamente as preparações do cardápio de escolas municipais da Grande São Paulo. 


\section{Metodologia}

Foi realizado estudo de delineamento transversal, no período de agosto a novembro de 2012, que avaliou qualitativamente o planejamento dos cardápios de 19 dias (aproximadamente quatro semanas) de escolas municipais das seguintes cidades da Grande São Paulo: Barueri, Guarulhos, São Bernardo do Campo e São Paulo. Foram considerados os cardápios das escolas em que os alunos matriculados permaneciam em período integral, realizando no mínimo cinco refeições no local, com faixa etária de um a três anos e 11 meses.

A coleta de dados para as cidades de Barueri e São Paulo foi realizada por meio dos cardápios disponibilizados nos sítios eletrônicos das respectivas prefeituras. Os cardápios da cidade de Guarulhos foram disponibilizados pela nutricionista do Departamento de Alimentação Escolar da Secretaria de Educação (DASE) e os cardápios da cidade de São Bernardo do Campo foram fornecidos pela nutricionista responsável pelo Departamento de Apoio à Educação do município.

O cardápio de São Paulo estava dividido em duas faixas etárias (1 ano a 1 ano e 11 meses e 2 anos a 3 anos e 11 meses), denominados São Paulo 1 e São Paulo 2, respectivamente.

Os cardápios foram avaliados através do método de Avaliação Qualitativa das Preparações dos Cardápios (AQPC) proposto por Veiros \& Proença, ${ }^{10} \mathrm{Com}$ adaptações, segundo os seguintes critérios:

- presença de frutas ou sucos de frutas naturais (não acrescido de água e açúcar);

- presença de hortaliças;

- frequência mensal de laticínios;

- presença de alimentos ricos em enxofre: foram analisadas as preparações do almoço e do jantar (com exceção do feijão, visto que o guia alimentar recomenda o consumo diário), avaliando a presença dos seguintes alimentos sulfurados: abacate, acelga, aipo, alho, amendoim, batata-doce, brócolis, castanha, cebola, couve-de-bruxelas, couve-flor, ervilha, feijão, gengibre, goiaba, jaca, lentilha, maçã, melancia, melão, milho, mostarda, nabo, nozes, ovo, rabanete, repolho e uva. Considerou-se como rico em enxofre quando dois ou mais alimentos citados eram oferecidos na refeição do mesmo dia; ${ }^{2,13}$

- presença de doces servidos no mês: foram considerados alguns produtos industrializados que contêm açúcar como um de seus principais ingredientes, como bebidas lácteas, achocolatados, suco artificial, gelatina, bolo, bolacha doce, mingau e flocos de milho;

- monotonia de cores: as grandes refeições foram avaliadas de acordo com o número de cores. Foi considerado monótono quando pelo menos $50 \%$ dos alimentos apresentaram cores semelhantes; 
- técnicas de cocção empregadas nas preparações proteicas;

- tipos de prato proteico oferecido nas grandes refeições, classificados em: carne bovina, embutido, frango, ovo e peixe.

O método AQPC foi aplicado considerando-se primeiro a avaliação dos cardápios diários; em seguida os semanais; e por fim a avaliação de cardápios mensais. A avaliação mensal agrupou os dados semanais e, posteriormente, estes foram tabulados em percentuais em relação ao número total de dias dos cardápios investigados.

\section{Resultados}

Dos cinco cardápios mensais analisados, as médias de porções semanais de fruta/suco oferecidas nos diversos municípios foram: 14,25 em Barueri; 3,75 em Guarulhos; 9,5 em São Bernardo do Campo; e 13,25 em ambos os cardápios de São Paulo.

A tabela 1 apresenta a avaliação mensal dos cardápios das cidades.

Tabela 1. Distribuição da análise qualitativa dos cardápios quanto à porcentagem de dias em que houve a ocorrência de cada critério considerado. São Paulo, 2012.

\begin{tabular}{lccccc}
\hline \multicolumn{1}{c}{ Municípios } & $\begin{array}{c}\text { Frutas } \\
(\%)\end{array}$ & $\begin{array}{c}\text { Hortaliças } \\
(\%)\end{array}$ & $\begin{array}{c}\text { Laticínios } \\
(\%)\end{array}$ & $\begin{array}{c}\text { Doce } \\
(\%)\end{array}$ & $\begin{array}{c}\text { Enxofre } \\
(\%)\end{array}$ \\
\hline Barueri & 100 & 100 & 100 & 100 & 58 \\
Guarulhos & 79 & 63 & 100 & 100 & 21 \\
São Bernardo do Campo & 100 & 100 & 100 & 100 & 26 \\
São Paulo 1* & 100 & 100 & 100 & 53 & 74 \\
São Paulo 2** & 100 & 100 & 100 & 53 & 58 \\
\hline
\end{tabular}

*Cardápio de 1 - 1 ano e 11 meses ** Cardápio de 2 - 2 anos e 11 meses

Ao comparar a oferta de frutas e doces (figura 1), constatou-se a presença de frutas nos cardápios de todas as cidades, porém nota-se a constante presença de doces, como em Guarulhos, onde a prevalência de doces mostrou-se a mais elevada - 40 preparações doces em 19 dias - ultrapassando o número de frutas servidas no mês. Na cidade de Guarulhos foram servidas, em média, duas preparações doces por dia, enquanto Barueri, São Bernardo do Campo e São Paulo apresentaram média de $1,6,1$ e 0,6 , respectivamente. 


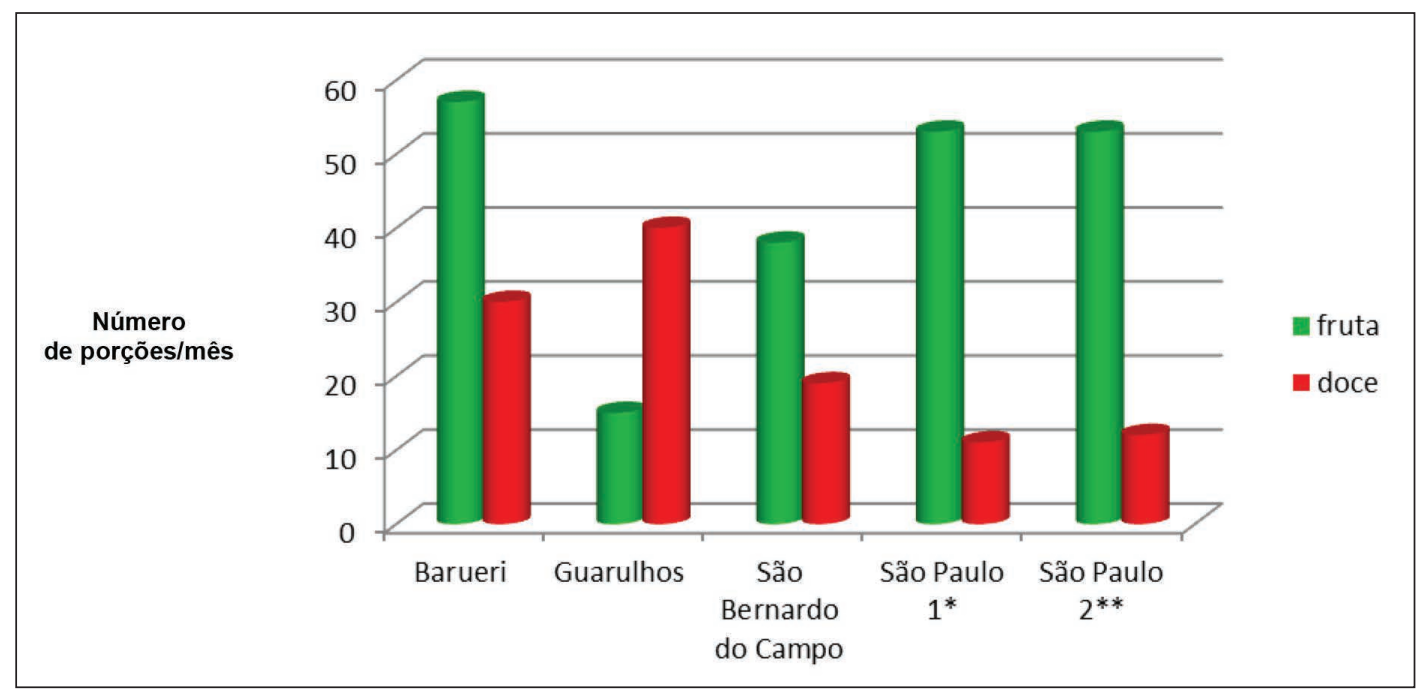

Figura 1. Distribuição da presença de frutas e doces no cardápio mensal das escolas. São Paulo, 2012.

*Cardápio de $1-1$ ano e 11 meses ** Cardápio de 2 - 2 anos e 11 meses

Refeições com pouca diversidade de cor interferem na aceitação da criança, pois a monocromia torna a refeição pouco atraente. A tabela 2 apresenta a avaliação da adequação das cores no cardápio.

Tabela 2. Distribuição percentual da análise qualitativa de cores das grandes refeições. São Paulo, 2012.

\begin{tabular}{lcccc}
\hline \multicolumn{1}{c}{ Cor } & \multicolumn{2}{c}{ Almoço } & \multicolumn{2}{c}{ Jantar } \\
& Colorido & Monótono & Colorido & Monótono \\
& $(\%)$ & $(\%)$ & $(\%)$ & $(\%)$ \\
\hline Barueri & 95 & 5 & 42 & 58 \\
Guarulhos & 63 & 37 & 74 & 26 \\
São Bernardo do Campo & 79 & 21 & 47 & 53 \\
São Paulo 1* & 47 & 53 & 47 & 53 \\
São Paulo 2** & 63 & 37 & 79 & 21 \\
\hline
\end{tabular}

*Cardápio de 1 - 1 ano e 11 meses ** Cardápio de 2 - 2 anos e 11 meses 
Em São Paulo não houve análise das técnicas de cocção das preparações proteicas, pois o cardápio disponibilizado não as discriminava, deixando a escolha da técnica para a pessoa responsável pelo preparo da merenda, de acordo com o receituário padrão disponibilizado pelas prefeituras para as escolas. A distribuição dos métodos de cocção das preparações proteicas encontra-se na tabela 3. Nota-se que o cozimento foi a técnica culinária mais utilizada no almoço e no jantar para as cidades avaliadas nesse critério.

Tabela 3. Distribuição percentual da análise dos métodos de cocção dos pratos proteicos das grandes refeições. São Paulo, 2012.

\begin{tabular}{lcccccc}
\hline & \multicolumn{3}{c}{ Almoço } & \multicolumn{3}{c}{ Jantar } \\
\cline { 2 - 7 } Técnicas de cocção & $\begin{array}{c}\text { Assado } \\
(\%)\end{array}$ & Cozido & Frito & Assado & Cozido & Frito \\
& 26 & 68 & 5 & 0 & 100 & 0 \\
\hline Barueri & 0 & 89 & 11 & 0 & 89 & 11 \\
Guarulhos & 5 & 89 & 5 & 0 & 100 & 0 \\
São Bernardo do Campo & 5 & & $(\%)$ & $(\%)$ & 0 \\
\hline
\end{tabular}

Em todas as cidades (figura 2), o cardápio apresentou maior prevalência de carne bovina, seguida de frango. A oferta de prato proteico na cidade de Barueri foi menor, pois o mesmo é oferecido com baixa frequência do jantar. Não foi observada previsão de peixe no cardápio de São Bernardo do Campo e São Paulo 2. Em Guarulhos, 50\% da oferta de peixe (2 refeições) apresentaram atum enlatado. Os embutidos não foram ofertados no cardápio de São Paulo (1 e 2). Já o ovo foi oferecido em média uma vez por semana em todas as cidades, com exceção de Barueri, onde o mesmo foi previsto em apenas dois dias do mês (figura 2). 




Figura 2. Distribuição mensal da oferta de prato proteico previstos nos cardápios no período de 4 semanas. São Paulo, 2012.

*Cardápio de 1 - 1 ano e 11 meses ** Cardápio de 2 - 2 anos e 11 meses

\section{Discussão}

De acordo com a análise dos cardápios dos diferentes municípios segundo o método AQPC, observou-se que a quantidade de frutas e hortaliças atingiu o preconizado pelo PNAE (3 porções de fruta e hortaliças semanais) em todos os locais estudados. ${ }^{11}$

Com exceção de Guarulhos (79\%), todas as cidades apresentaram oferta de frutas em 100\% dos dias, diferentemente dos resultados encontrados por Christmann, ${ }^{14}$ que avaliou uma escola estadual da cidade de Guarapuava-PR, e de Menegazzo et al., ${ }^{4}$ que avaliaram os cardápios de uma escola estadual na cidade de Florianópolis-SC, ambos pelo método AQPC. Nos dois estudos, a oferta de fruta foi verificada em apenas $4 \%$ do mês, uma única vez. Essa melhoria pode ser decorrente do aumento do repasse per capita do PNAE, ${ }^{15}$ que passou de $\mathrm{R} \$ 0,66$ na época em que os estudos de Christmann ${ }^{14}$ e Menegazzo et al. ${ }^{4}$ foram realizados, para $\mathrm{R} \$ 1,00,{ }^{16}$ o que pode ter possibilitado uma melhoria nos cardápios. 
A presença de hortaliças nos cardápios (tabela 1) foi constatada em todos os dias, exceto em Guarulhos (63\%). Menegazzo et al. ${ }^{4}$ encontraram em seu estudo a oferta de legumes e verduras somente em $48 \%$ dos dias, e Christmann ${ }^{14}$ em todos os dias, porém nesta escola havia uma horta orgânica, o que pode ter facilitado essa oferta.

Os hábitos alimentares são formados na infância, portanto, a alimentação oferecida nas creches deve ser equilibrada, a fim de estimular o consumo de alimentos saudáveis ${ }^{1}$. Frutas, legumes e verduras (FLV) são essenciais para o desenvolvimento, pois são fontes de vitaminas, minerais e fibras alimentares. A ingestão desses alimentos é um fator protetor para o risco de DCNTs. ${ }^{2}$ Também foi observada adequação da oferta de FLV para crianças de 2 a 10 anos no almoço em uma escola privada de São Paulo, segundo descreveram por Pioltine e Spinelli.. ${ }^{17}$

Observou-se que o leite foi oferecido pelo menos uma vez ao dia em todas as escolas pesquisadas. Por se tratar de instituições de ensino infantil, onde as crianças fazem no mínimo cinco refeições diárias, seria recomendável maior oferta de leite e derivados, visto que esses alimentos são fontes de cálcio, mineral essencial para o desenvolvimento e maturação óssea. No entanto, o PNAE ${ }^{11}$ não estabelece a frequência semanal nem a quantidade de porções que devem ser servidas. Leite e derivados são fontes de proteínas, cálcio e vitaminas, e, segundo a pirâmide alimentar para crianças de dois a três anos, deve-se consumir três porções diárias de alimentos desse grupo, ${ }^{18}$ a fim de atingir $700 \mathrm{mg} /$ dia, teor recomendado pelas Dietary Reference Intakes ${ }^{19}$ para crianças de um a três anos.

Observa-se, na tabela 1, que nas cidades de Barueri e São Paulo, em mais da metade dos dias, as refeições continham duas ou mais preparações com alimentos sulfurados (saladas e sucos). Alimentos ricos em enxofre podem produzir flatulência e desconforto abdominal, o que pode levar à falta de atenção e à diminuição do rendimento escolar, por isso esses alimentos não devem ser servidos em grandes quantidades. ${ }^{14}$ No estudo de Christmann, ${ }^{14} 52 \%$ dos dias continham refeições com alimentos sulfurados que, à semelhança do que ocorre no presente estudo, foram servidos em forma de salada.

O Guia Alimentar para a População Brasileira² preconiza a ingestão diária de no máximo uma porção de doce, mostrando uma adequação em São Bernardo do Campo e em São Paulo. Nas cidades de Barueri (1,6 porção) e Guarulhos (2 porções), entretanto, foram servidas mais de uma preparação desse tipo por dia, semelhante ao resultado encontrado por Menegazzo et al., ${ }^{4}$ evidenciando-se assim a necessidade da adequação do cardápio.

Em relação à monotonia de cores no almoço, a cidade de São Paulo foi a única que apresentou acima de $50 \%$ de inadequação na hora do almoço (tabela 2) para as crianças maiores de dois anos. Em contrapartida, na cidade de Barueri, a refeição era colorida em 95\% dos dias. Com relação ao jantar, Barueri, São Bernardo do Campo e São Paulo apresentaram, respectivamente 58, 53 e 53\% 
de refeições monótonas, o que pode ser decorrente do tipo de refeição servida, pois, na maioria das vezes, são servidas preparações únicas, como sopas, purês e polentas. Quando há monotonia de cores no cardápio, a ingestão de nutrientes também fica prejudicada, pois uma refeição colorida oferece maior variedade de nutrientes. ${ }^{2}$

Os resultados encontrados na presente pesquisa (tabela 2) diferem daqueles encontrados por Menegazzo et al., ${ }^{4}$ que observaram monotonia em apenas 12\% das grandes refeições. Já no estudo de Veiros \& Proença ${ }^{10}$ que avaliaram qualitativamente as preparações do cardápio de uma Unidade de Alimentação e Nutrição, 65,1\% das refeições eram monótonas.

A baixa incidência de pratos proteicos fritos (tabela 3), principalmente nos municípios de Barueri e São Bernardo do Campo, apresenta efeito positivo sobre a saúde e formação dos hábitos alimentares das crianças. No estudo de Christmann, ${ }^{14}$ a prevalência foi maior para pratos assados (56\%). Costa e Mendonça ${ }^{5}$ avaliaram qualitativamente os cardápios, comparando uma creche pública e uma particular do Distrito Federal, e constataram que apenas 1,19 e 3,3\% das preparações eram fritas, respectivamente.

Pode-se observar (figura 2) que a distribuição dos tipos de carnes nos cardápios privilegia a oferta de carne vermelha necessária para o provimento de ferro, nutriente essencial nessa faixa etária vulnerável à anemia. Brunken et al. ${ }^{20}$ encontraram alta prevalência de anemia em crianças menores de três anos, frequentadoras de creches públicas. Alimentos de origem animal, como carnes e ovos, possuem todos os aminoácidos essenciais necessários para o crescimento e manutenção do indivíduo e são fontes de ferro e vitamina $\mathrm{B}_{12 .}{ }^{2}$

Resultados semelhantes foram encontrados por Assis, ${ }^{21}$ que avaliou qualitativamente o cardápio de uma unidade produtora de refeição de um hospital universitário, apontando que a carne vermelha é a mais servida (61,9\%), seguida de frango (26,19\%) e carne suína (9,52\%).

Observou-se nas cidades de Barueri, Guarulhos e São Bernardo do Campo a presença de embutidos. Os derivados de carne, como salsicha, linguiça, presuntos e outros embutidos contêm, em geral, excesso de gordura saturada, conservantes e sódio, assim seu consumo deve ser moderado, pois a elevada ingestão dos mesmos pode levar ao desenvolvimento de DCNTs. ${ }^{2,22}$ Os enlatados foram servidos apenas em Guarulhos (macarrão com atum), sendo sua frequência no cardápio de 10\%. Assim como os embutidos, os enlatados possuem grandes quantidades de sódio e conservantes e devem ser consumidos com moderação. ${ }^{2,22}$

Os peixes contêm proteína de boa qualidade, necessárias para o crescimento e manutenção do organismo, são ricos em ácidos graxos essenciais e fonte importante de vitamina $\mathrm{B}_{12}$. Peixes foram servidos em Barueri, Guarulhos e São Paulo, porém sua oferta foi baixa quando comparada à oferta de outros pratos proteicos. Este resultado foi semelhante ao de Assis, ${ }^{21}$ segundo o qual 
peixes foram servidos em apenas 2,38\% dos dias. Isto possivelmente ocorre devido ao elevado custo mercadológico, que dificulta a inclusão deste alimento no cardápio, visto que o valor repassado para a aquisição dos gêneros alimentícios é limitado. ${ }^{2}$ Segundo a Agência Brasil, apenas 26,9\% (cerca de 1,5 mil) das 5.565 prefeituras em todo o país incluem o pescado no cardápio da merenda escolar pelo menos uma vez por semana. Isso ocorre por dificuldades várias, tais como câmaras frigoríficas na escola para estocar o alimento, habilidade das merendeiras no preparo do pescado e a facilidade ou não na aquisição de peixe fresco na cidade..$^{23}$

Diante do exposto, o planejamento dos cardápios das escolas municipais em geral mostrouse adequado, mas deve-se atentar para a prevalência de doces e alimentos sulfurados, de modo a melhor atender às necessidades das crianças. Para manter a adequação dos cardápios, são necessárias avaliações periódicas e, para garantir que o planejado seja executado, são necessárias avaliações da qualidade da alimentação infantil. Caso se constatem inadequações, estas devem ser corrigidas. ${ }^{7,5}$

\section{Conclusões}

De modo geral, os cardápios avaliados estão adequados em relação à oferta de frutas, hortaliças e laticínios e à técnica de cocção empregada no preparo do prato proteico, de acordo com o método de avaliação utilizado neste trabalho. No entanto, sugere-se a revisão da frequência do emprego de alimentos sulfurados e doces no cardápio.

Para garantir uma alimentação escolar adequada, faz-se necessária uma análise da execução do planejamento dos cardápios nas respectivas creches, como etapa posterior na avaliação da qualidade da alimentação infantil. Também sugere-se utilizar outras ferramentas de avaliação da qualidade das refeições oferecidas nas escolas, tais como um índice de refeição saudável, ou pontos de corte para os parâmetros (cores, técnicas de cocção, presença de frutas, produtos lácteos) utilizados no método AQPC.

\section{Referências}

1. Ramos M, Stein LM. Desenvolvimento do Comportamento alimentar infantil. J pediatr (Rio J). 2000;76:229-37.

2. Brasil. Ministério da Saúde. Secretaria de Atenção à Saúde. Guia alimentar para a população brasileira. Brasília (DF): Ministério da Saúde; 2005.

3. Sociedade Brasileira de Pediatria. Cadernos de Escolas Promotoras de Saúde - I. 2004. [acesso em 20 jun 2012]. Disponível em: http://www.bvsde.paho.org/bvsacd/cd57/cadernosbpfinal.pdf 
4. Menegazzo M, FracalossiI K, Fernandes AC, Medeiros NI. Avaliação qualitativa das preparações do cardápio de centros de educação infantil. Rev Nutr. 2011;2(24):243-51.

5. Costa SEP, Mendonça KAN. Avaliação qualitativa de cardápios oferecidos para pré-escolares de creches do Distrito Federal. Universitas: Ciências da Saúde. 2012;10(1):33-40.

6. Silva CC. Alimentação e crescimento saudável em escolares. In: Alimentação, atividade física e qualidade de vida de escolares do município de Vinhedo/SP. Campinas: IPES Editorial; 2009. p. 15-20.

7. Abreu ES, Spinelli MGN, Souza Pinto AM. Gestão de Unidades de Alimentação e Nutrição: um modo de fazer. São Paulo: Metha; 2011.

8. Brasil. Conselho Federal de Nutricionistas. Resolução/CFN no 465 de 23 de agosto de 2010. Dispõe sobre as atribuições do Nutricionista, estabelece parâmetros numéricos mínimos de referência no âmbito do Programa de Alimentação Escolar (PAE) e dá outras providências. Diário Oficial da União 16 jun. 2010.

9. Brasil. Ministério da Educação. Secretaria da educação. Alimentação Escolar: Dados estatísticos. Brasília (DF): FNDE; 2012.

10. Veiros MB, Proença RPDC. Avaliação qualitativa das preparações do cardápio em uma unidade de alimentação e nutrição - método AQPC. Nutr Pauta. 2003;11(62):36-42.

11. Brasil. Ministério da Educação. Secretaria da educação. Resolução/CD/FNDE nº 38, de 16 de julho de 2009a. Dispõe sobre o atendimento da alimentação escolar aos alunos da educação básica no Programa Nacional de Alimentação Escolar - PNAE. Diário Oficial da União 17 jun 2009.

12. Proença RPC, Qualidade nutricional e sensorial na produção de refeições. Florinópolis: EdUSFC; 2005.

13. Reis NT. Nutrição clínica: sistema digestório. Rio de Janeiro: Livraria Rubio; 2003.

14. Christmann AC. Avaliação qualitativa das preparações do cardápio - método AQPC - e resto-ingestão de um colégio em regime internato de Guarapuava-PR [trabalho de conclusão de curso]. Guarapuava: Universidade Estadual do Centro-Oeste; 2011.

15. Brasil. Fundo Nacional de Desenvolvimento da Educação. Resolução/FNDE/CD/N. 67, de 28 de dezembro de 2009. Altera o valor per capita para oferta da alimentação escolar do Programa Nacional de Alimentação Escolar - PNAE. Diário Oficial da União 29 dez 2009.

16. Brasil. Ministério da Educação. Secretaria da educação. Resolução no 8, de 14 de maio de 2012. Altera os valores per capita da educação infantil no âmbito do Programa Nacional de Alimentação Escolar (PNAE). Diário Oficial da União 6 mar 2012.

17. Pioltine MB, Spinelli MGN. Análise da oferta alimentar em uma escola privada do município de São Paulo. Revista Univap. 2012;18:48-57.

18. Philippi ST, Cruz ATR, Colucci ACA. Pirâmide alimentar para crianças de 2 a 3 anos. Rev Nutr. 2003;16(1):5-19.

19. Institute of Medicine (US). Dietary Reference Intakes for calcium, phosphorus, magnesium, vitamin D, and fluoride. National Academy Press. 1997:71-313. 
20. Brunken GS, Guimarães LV, Fisberg M. Anemia em crianças menores de 3 anos que frequentam creches públicas em período integral. J pediatr (Rio J). 2002;78(1):50-6.

21. Assis J. Análise qualitativa das preparações oferecidas no cardápio da unidade produtora de refeições de um hospital universitário. Rev Nutrição em foco [periódico da Internet]. 2008 set 19 [acesso em 2012 out 10]; Disponível em: http://www.nutricaoemfoco.com.br/pt-br/site.php?secao=auannefdebate \&pub=860.

22. Sociedade Brasileira de Pediatria. Departamento de Nutrologia. Manual de orientação: alimentação do lactente, alimentação do pré-escolar, alimentação do escolar, alimentação do adolescente, alimentação na escola. São Paulo: Sociedade Brasileira de Pediatria; 2006.

23. Agência Brasil. Apenas $27 \%$ das prefeituras usam pescado na merenda escolar semanalmente, diz ministro. [acesso em 2013 set 09] Disponível em: http://www.brasil.gov.br/noticias/ arquivos/2012/05/10/apenas-27-das-prefeituras-usam-peixe-na-merenda-escolar-semanalmentediz-ministro. 
